\title{
Guía para el arbitraje de manuscritos \\ Revista Argentina de Cardioangiología Intervencionista (RACl)
}

Revista Argentina de Cardioangiología Intervencionista 2014;5(3):173-174

Es un honor ser invitado como árbitro de una publicación científica. También es una responsabilidad. La reputación de la revista depende, en parte, del proceso de revisión por pares científicos.

Este texto permite, de forma breve, servir de guía para arbitrar un manuscrito de la Revista Argentina de Cardioangiología Intervencionista (RACI)

\section{GUÍA PARA EVALUAR UN MANUSCRITO}

Antes de comenzar, por favor tenga en cuenta los siguientes puntos para decidir usted si va a revisar o no un manuscrito de la RACI.

- Asegúrese de que el manuscrito que le enviaron tiene relación directa con su especialidad. El editor que le envió el manuscrito puede que no conozca su trabajo en forma detallada; por favor, acepte invitaciones si cree ser competente para realizar la revisión del manuscrito, de lo contrario informe al editor inmediatamente para que este pueda asignarle el manuscrito a otro especialista.

- Evite potenciales conflictos de intereses. Pueden existir conflictos de índole personal, profesional o financiero, en donde usted, como árbitro, crea que no puede realizar una evaluación imparcial u objetiva, libre de sesgo profesional o personal. Sin embargo, un conflicto de intereses puede que no lo elimine como candidato para arbitrar un manuscrito. Por ejemplo, si trabaja en el mismo departamento o institución que alguno de los autores o si trabajó con alguno de los autores. Si tuviera alguna duda, por favor póngase en contacto con el editor en jefe para comunicarle los posibles conflictos y será él quien decidirá si es apropiado o no que usted revise el manuscrito.

- Tenga en cuenta el tiempo disponible. La revisación de un manuscrito consume tiempo, y puede que varíe de forma significativa de acuerdo con el tipo de artículo o con su contenido. Según información provista por la editorial Elsevier, el promedio de tiempo para realizar una revisión es de 5 horas. Por favor, considere si usted puede realizar la revisión completa, junto con el informe y sus comentarios, en un período no mayor a 2 (dos) semanas. Si usted está dispuesto a evaluar el manuscrito pero de antemano sabe que no podrá realizarlo en el lapso indicado, comuníquese de forma inmediata con el editor en jefe para que este pueda tomar una decisión al respecto, por ejemplo extender el tiempo de evaluaciación del manuscrito y/o cambiar el árbitro. Es importante para toda la cadena de revisión/respuesta/corrección que esto sea realizado sin demora.

Una vez que usted decida ser árbitro, tenga en cuenta lo siguiente:

- Responsabilidad ética durante el proceso de revisión. El árbitro tiene que mantener la confidencialidad acerca de la existencia y el contenido del manuscrito revisado. Es inapropiado compartir el manuscrito o discutir los detalles de su contenido con otros antes de su publicación. Existen excepciones, que siempre deben ser aprobadas por el editor en jefe. Un ejemplo es cuando el árbitro le pide a un colega su colaboración para la revisión del manuscrito. Sin embargo, esa colaboración tiene que mantenerse bajo las mismas normas de confidencialidad y el editor en jefe tiene que ser informado acerca de esta situación.

- Conducta del árbitro. Los árbitros no deben utilizar el conocimiento del manuscrito antes de su publicación, para su beneficio personal. El conocimiento de la información del manuscrito solo debe utilizarse con el propósito de su revisión.

- Reporte dudas. El árbitro tiene la responsabilidad de notificar cualquier duda acerca de la ética del manuscrito, no solo en lo relacionado con publicaciones repetidas, fraude, plagio, sino también en cuanto a dudas acerca del uso de animales o humanos de acuerdo con lo reportado en el manuscrito. 


\section{Realizando la revisión}

A. Evaluación del manuscrito. Existen tres posibilidades al momento de clasificar un manuscrito:

- Rechazo (Explicar el motivo en el reporte al editor en jefe)

- Aceptación sin revisión.

- Revisión (mayor o menor)

Para realizar esta clasificación se deberá tener en cuenta lo siguiente:

1. Originalidad/Novedad

2. Importancia científica/Impacto

3. Metodología y Diseño experimental adecuado

4. Calidad de los datos, de la presentación y de los resultados

5. Prioridad científica para su publicación basado en la siguiente escala, según su criterio:

a. Prioridad alta

b. Prioridad media/alta

c. Prioridad estándar

d. Prioridad media/baja

e. Cuando la escala no se aplica al manuscrito evaluado, deberá aclararlo.

Los manuscritos rankeados dentro de la prioridad alta son los que posiblemente se publiquen. El árbitro también debe realizar una recomendación, o no, para su publicación.

6. Indicar si existen dudas acerca de la metodología estadística utilizada o si existen consideraciones éticas.

B. Comentarios confidenciales al editor en jefe. Resumir las razones de su evaluación y ranking y las recomendaciones. Enumerar específicamente los aspectos originales y de importancia del manuscrito, justificando los mismos. Esta información no será enviada a los autores. Informar además si usted esta dispuesto a revisar nuevamente las respuestas de los autores, en caso de que sea necesaria una revisión (mayor o menor)

C. Comentarios para los autores. Los comentarios o preguntas hacia los autores (que éstos leerán) no deben tener ninguna observación o acotación que indique al autor su opinión como árbitro acerca de si el manuscrito tiene o no que ser publicado. Todos los comentarios tienen que tener una actitud crítica pero positiva, con espíritu constructivo. El árbitro tiene que discutir las debilidades y fortalezas del manuscrito. Se deberá tener en cuenta, a la hora de realizar los comentarios a los autores:

1. Originalidad e importancia científica.

2. Longitud y relación del título con el texto.

3. Resumen adecuado, en cuanto al contenido y a la cantidad de palabras.

4. Introducción, razón del estudio y claridad de la hipótesis planteada.

5. Diseño del estudio adecuado, metodología aplicada y análisis estadístico correcto.

6. Lineamientos del manuscrito con la revista, incluyendo tablas y figuras.

7. Interpretación de los datos por parte de los autores.

8. Longitud y adecuación de la discusión.

9. Inclusión de referencias recientes y apropiadas.

10. Lenguaje correcto.

Los comentarios y/o preguntas a los autores tienen que estar numeradas.

Por último, desde la revista RACI le recomendamos:

1. Ser crítico, y justificar sus críticas.

2. No repetir la información del manuscrito, solo citar página y renglones, al momento de enviar su respuesta

3. Chequear el espíritu de la revista al momento de revisar el manuscrito.

4. Chequear las instrucciones para enviar un manuscrito a la revista.

5. Dar recomendaciones claras.

6. Numerar los comentarios.

7. Ser específico, indicar exactamente que es lo que usted cree que debe ser modificado en el texto.

8. No identificarse en los comentarios 